\title{
EDUCATIONAL METHODS OF THE NEW CURRICULUM IN LIVERPOOL
}

\author{
M Flanagan, Undergraduate Sub-Dean \\ Morecambe Bay
}

Everything we do to prepare for the arrival of the pilot group of Year 4 students in September 2003 must be underpinned by a firm understanding of the Liverpool curriculum. This requires more than a willingness simply to study the curriculum; it requires personal and corporate commitment to the educational methods of the medical school and the abandonment of some of our expectations (which are founded in our own experiences as students and teachers). It probably requires a leap of faith that the new approach is better than the status quo.

Broadly speaking, most of us had an undergraduate experience typified by lectures and tutorials delivered in a syllabus directed by our teachers. We moved from directed learning in school to more of the same at university, jumping over the hurdles of exams with an increasing burden of learned and memorised material in our heads. When we met patients, eventually, on the wards, they were 'disease subjects' for us to devour. We knew precious little of the realities of their lives outside hospital. We knew nothing at all about critical enquiry and research techniques which might have given access to better information and a deeper insight into their conditions.

Examinations were the dominant method of assessment. We were graded, ranked, passed, failed or selected for future careers according to the beliefs of our universities, a do-ordie experience which had the benefit of being easily understood. Developmental assessment rarely occurred but we didn't know we were missing the benefits of feedback (which provides motivation and helps learning) or insights into our strengths and weaknesses. We did not reflect on our progress except in private or in company with our friends or when we were in trouble. The triumph of qualification was soon deflated by the hard slog of our house jobs. Despite this, most of us turned into good doctors, mainly because we are academically able and joined effective postgraduate training programmes. My purpose in describing some of the old curriculum is partly to highlight the areas of change and partly to say that change was needed, despite our successes under the old system. The sheer weight of data, rapid computer access to information, the expectations of the public and the profession, plus the seismic changes in society have made change unavoidable and desirable. Evangelists for 'the new way' can make one feel bad about the past but there is no shame in how we got to where we are now. It's just that the medical educators have formed a consensus that there's a better way, and that's where we are going.

The GMC wrote a seminal document in the 1990s called 'Tomorrow's Doctors' which gave clear directives for change to the medical schools. The need to understand adult learning styles and develop self-directed learning by students were linked with a drive to reduce factual knowledge and to develop new methods of assessment. 'The patient' would soon take centre stage.
Liverpool responded with a radical new curriculum in 1996. The faculty of medicine made a determined effort to embrace problem-based learning (PBL) for the good of students and patients. It undertook the hard task of driving important elements of our postgraduate learning into the undergraduate arena. These include communicating with patients and each other, teamwork, management, research and critical evaluation of scientific data. None of this was comfortable for senior doctors. Even now in its sixth year some colleagues in Liverpool have still not got used to the loss of the old ways.

There is no turning back. As one example, the anatomy dissection room is now restricted to students of pure anatomy. Medical students learn anatomy as and when required. They do so using clinical skills labs, the human anatomy resource centre (HARC) which is packed with plastic models, dry bones, specimens and radiology pictures, and the web-based Virtual Resource Centre.

The paramount fact to grasp is that the responsibility for learning now rests squarely on the individual student. The university and medical communities like us in Morecambe Bay no longer have to deliver a syllabus. Our duties are to

- set the educational environment

$\begin{array}{r}6 \text { responsibility for } \\ \text { learning now rests } \\ \text { squarely on the } \\ \text { individual student } 9 \\ \hline\end{array}$

- provide access to clinical material

- provide support, give feedback and partake in the assessment of students

\section{THE CURRICULUM IN YEAR 4}

Remember, a pilot group of 24 students will spend 36 weeks of the year between September 2003 and July 2004 in Morecambe Bay. They will do

- eight weeks medicine, four weeks care of the elderly

$=12$ weeks

- eight weeks surgery, four weeks palliative care $=12$ weeks

- four weeks obs/gynae, four weeks paediatrics, four weeks psychiatry

$\underline{=12 \text { weeks }}$

36 weeks

In that time they will

- spend a compulsory minimum of two days in hospital

- have one compulsory day in primary care

- have two days to use as they choose. In practice this is usually spent in the hospital and its library 
- work through a published list of 'core cases'

- use log books to record these cases which then form part of the clinical assessment at the end of the block

- conduct their own PBL study groups for key topics

- prepare for and sit the summative exams in May or June. These are formal pass/fail exams analogous to our finals

- apply for PRHO jobs in August of the following year, ie Year 5

- do SSM 6

\section{WHAT THIS MEANS FOR US}

\section{Cutting the cloth}

There is very little time in each clinical rotation. It seems impossible to believe that 'appropriate experience' in individual specialities can be gained. Indeed, some professional associations have described a core curriculum recommended for undergraduates which is in direct conflict with Liverpool's core cases and would require ages to deliver. We need to remember the following:

a) students will have done three years' study before reaching us and will have good clinical and communication skills and an understanding of normal structure and function. Year 4 focuses on abnormal structure and function.

b) we must accept the primacy of their core cases over our expectations. We are facilitating skills and knowledge appropriate to Year 4 only.

c) students work in pairs and do a day a week in primary care. They are less visible than people on clinical attachments. We have to trust them.

\section{A new breed}

They are a new type of student with less 'held' knowledge, who are used to finding out things. Typically, they can be quite challenging, often ask hard questions which we cannot answer and are hungry for feedback. Later in the year they are avid for mock long case exams

The challenge for us is to be open about the limits of our knowledge and to talk honestly when things go wrong.

\section{The educational environment}

This must be satisfactory for both students and teachers. Teachers may be nurses, physios, non-consultant doctors, lab technicians - anyone who is interested and contributes under the direction of senior doctors. The key elements for success are:

- widespread understanding of the curriculum

- enthusiasm

- preparedness

- a structured timetable

- a good welcome

- ready access to computers, printers and the library

\section{Effective planning}

Good liaison is needed between general practices and hospitals and between different specialities in each 12-week block. Following a case in psychiatry, for example, might be impossible in the allocated four weeks but could be achieved, by good planning and coordination, in the subsequent paediatric block

\section{Standards}

We must concentrate on setting standards, monitoring the experience of students and teachers, and undertaking assessment.

In September 2004 we receive our first full cohort of 50 students in Year 4.

\section{THE CURRICULUM IN YEAR 5}

This is an intensely experiential year designed to prepare students to become PRHOs. There are no exams but progress is monitored by a personal portfolio. This is a reflective record of achievement covering cases seen (relative to learning objectives), a skills log, courses or meetings attended, presentations given, papers written and more.

The record of in-training assessment (RITA) is an expert statement made by a supervisor following a review of the portfolio in conjunction with reflection and self-assessment by the student. RITAs occur at regular intervals and are completed at the end of each of the five blocks. They amount to a collection of professional statements that a student is 'fit to practise' as a PRHO. They are the student's responsibility. The blocks are

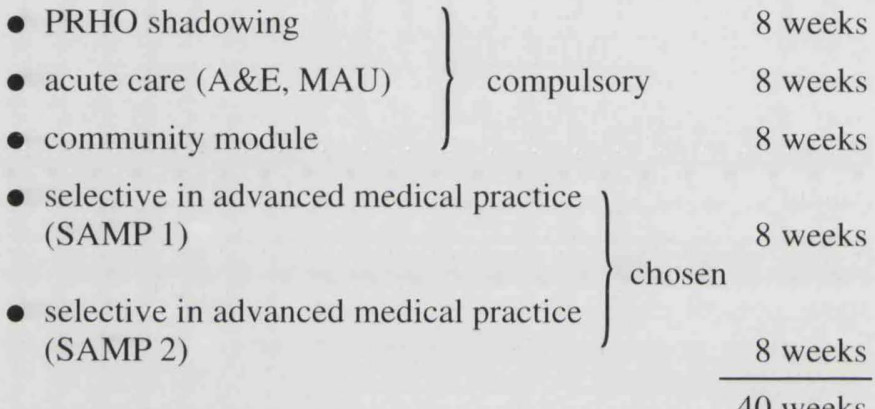

SAMPs allow students some choice to follow an interest or to fill gaps in their experience.

The most daunting thing about making RITA assessments effective is how to ensure appropriate standards of assessment by all members of any group. It is too easy to treat RITAs as a tick-box exercise. Teachers who do not engage adequately with the process run the risk of failing to give students the message that their performance is below par. The director of Year 5 is working to ensure good RITA performance.

\section{THE CURRICULUM ELSEWHERE}

Years 4 and 5 are not the only parts of the curriculum we shall deliver - though this was the original agreement between the parties concerned. The steering group has agreed that we should host special study modules (SSMs) which are compulsory four-week blocks of supervised study. They occur throughout the course but we aim to start with SSM3 and SSM4 in Year 3. Pairs of students attend one location for four weeks to investigate a subject of their choice. SSMs are a highly-structured means to develop the principles and practice of scientific thinking and investigation. The seven objectives are to

\section{- access relevant data}

- appraise the current status of the field of study

- plan a study or review

- conduct the study 
- draw relevant conclusions

- assess the limitations of the results and suggest future directions

- write it up

There are four types of SSM

- structured review of literature

- laboratory-based study

- survey-based study

- interpretive study

SSMs are assessed by a convenor, usually a consultant or GP, against the seven objectives. They count towards the final degree and are emphatically not an old-style clinical attachment.

\section{OUR IDENTITY AS EDUCATORS}

Embracing the educational methods of Liverpool does not mean that will shall become slaves to a new dogma.

Firstly, the curriculum is under constant surveillance and is changing each year in small ways. Much of these changes arise from open dialogue between the faculty and the students, which is impressive to observe. We shall be important contributors to this process.

Secondly, the high standards of our educational activity are well-recognised by the faculty. When coupled with our location and broad range of clinical opportunities, our contribution to the partnership is desired just as highly by Liverpool University as is theirs by us. We have an equal worth. It is expected that we shall bring our standards to undergraduate training. We shall have considerable latitude to develop timetables, monitor student attendance and oversee their conduct.

Students may clamour for tutorials or what David Gorst calls 'spoon feeding'. A small amount of this is desirable; after all, we are repositories of valuable clinical experience. So long as a mental checklist of their educational methods and timetable is kept to the fore, then there is a place for such events. When thinking about opportunities or planning activity it is important to be self-disciplined. It is no use saying 'so and so would be a wonderful resource for students' unless the activity or encounter fits somewhere in the educational aims.

\section{SUMMARY}

Becoming an effective host for Liverpool students requires the Morecambe Bay medical community to

- understand their educational ethos

- be prepared to change our expectations

- embrace their educational techniques of supervision and assessment

- create a new learning environment sensitive to the curriculum

- pay detailed attention to our specific roles in Years 4 and 5, and to SSMs in Year 3

Starting in the next academic year, there will be a rolling programme of instruction about the specific features mentioned thus far. A lot of data can be accessed on the faculty website $w w w . l i v . a c . u k$. We expect to import most of this data onto our trust intranet very shortly and will also develop a website of our own in May. Everything will be posted there.

Finally, we don't need to worry unduly about our individual skills as teachers. We are doing most of it already in a slightly different form. This is a consistent message from colleagues in other Liverpool teaching DGHs, notably Whiston. We do not have to 'reinvent the wheel' and good practice established elsewhere will not be difficult to import provided that we trust the validity of the new curriculum. We have the huge advantage of starting with a clean sheet, unlike our colleagues elsewhere who had to run the old and new curricula at the same time. 